\title{
Tissue lipids in calves suffering from muscular dystrophy
}

\author{
By RITVA POUKKA \\ Department of Biochemistry, College of Veterinary Medicine, \\ Helsinki, Finland
}

(Received 6 Fuly 1965-Accepted 24 fanuary 1966)

\begin{abstract}
I. Lipids of the heart muscle, skeletal muscle and liver were investigated in healthy calves and in calves suffering from enzootic muscular dystrophy with special regard to the fatty acid composition of the phospholipids and triglycerides. 2. Healthy young calves and older calves differed in the fatty acid composition of these tissues. The tissue phospholipids of healthy young calves contained less linoleic acid and more monounsaturated fatty acids than those of older calves. Of the saturated fatty acids, palmitic acid content tended to be higher in young calves and stearic acid content tended to be higher in older calves. 3 . The stearic acid content of tissue triglycerides was lower in young calves than in older calves. 4 . Fatty aldehydes were present in the phospholipid fraction of the heart muscle and of the skeletal muscle. Stearaldehyde content was higher in older calves than in young calves. 5. In calves with muscular dystrophy definite changes in the fatty acid composition of the phospholipids were found. In young calves the content of linoleic acid was higher and that of monounsaturated fatty acids lower in tissues of diseased animals than in the corresponding tissues of healthy controls. Both in young and older calves arachidonic acid content was higher in the degenerated areas of the skeletal muscle than in the healthy controls. 6. Possible relationships between the tocopherol and arachidonic acid contents of the tissues are discussed. 7 . In the triglyceride fraction the differences between diseased and healthy tissues were less significant than in the phospholipid fraction in young calves. In older calves no significant differences were found. 8 . An increase in lipid content was found in the degenerated areas of the skeletal muscle and a decrease in livers from diseased animals. An increase in free cholesterol was found in the degenerated areas of the skeletal muscle. The triglyceride content of livers from diseased animals was decreased. The relative proportion of phospholipids was less in skeletal muscle and higher in liver of diseased animals than in the corresponding tissues of healthy controls.
\end{abstract}

Muscular dystrophy, white muscle disease, of calves is a disease of considerable economic importance in many parts of the world including Finland. Most cases occur in the spring between February and June (Andersson, 1960), but also a somewhat longer disease period, lasting from the late autumn to the early summer, has been reported for young calves (Oksanen, I965). Calves are most often affected from birth up to 6 months of age.

The pathogenesis of muscular dystrophy is far from clear. Divergent views are to be found in the literature, but three factors have most often been discussed in connexion with the disease, namely, vitamin $E$, selenium and unsaturated fatty acids.

Unsaturated fatty acids play an important part in experimentally produced muscular dystrophy. In some experiments it has not proved possible to produce the disease without inclusion of unsaturated fats in the diet (Adams, Gullickson, Sautter \& Gander, I954; Blaxter \& McGill, I955). Slagsvold \& Lund-Larsen (1934) showed that cod-liver oil given to calves produces a disease resembling muscular dystrophy. It was shown later by Blaxter and his colleagues (Blaxter, Watts \& Wood, I952; Blaxter, Brown, Wood \& MacDonald, I953) that cod-liver oil added to calf diets of skim milk produced severe muscular disease. They found that the toxic effect of cod-liver oil 
was very closely associated with its content of unsaturated fatty acids and that it was counteracted by vitamin $\mathbf{E}$. The same disease could be produced in calves by giving them lard as a source of fat.

Maize oil may also act as a dystrophogenic fat, since Adams, Gullickson, Gander \& Sautter (1959), Adams, Sautter, Gullickson \& Gander (1959) produced muscular dystrophy experimentally in calves given filled milk containing maize oil. In these experiments skim milk, alone or with hydrogenated maize oil, failed to produce dystrophy. Barker, Wise \& Jacobson (1952) found that crude soya-bean oil was an unsatisfactory substitute for milk fat in the diet of young calves, whereas freshly processed hydrogenated soya-bean oil was satisfactory.

As is evident from the foregoing, unsaturated fatty acids play an important part in the experimentally induced disease of calves. It is, however, much less clear what role the unsaturated fatty acids may have in naturally occurring muscular dystrophy of calves.

The purpose of the work now described has been to approach this problem by investigating the fatty acid composition of the tissues which become affected in muscular distrophy, namely, heart muscle and skeletal muscle. As the liver is the key organ in fatty acid metabolism, this tissue has also been studied. The amount of different lipid components and the content of total lipids in these tissues have also been investigated.

\section{EXPERIMENTAL}

Collection of samples. The tissue samples were collected between the autumn of I96I and the spring of 1964 . The tissue samples were obtained from the slaughterhouse of the city of Helsinki. All the material examined came from the province of Pohjanmaa, where muscular dystrophy occurs enzootically. In that region the selenium content of forage has been found to be low (Oksanen, 1965). At the same time as the samples were collected from the animals with muscular dystrophy, other samples were taken from healthy animals coming from the same area. The samples of skeletal muscle were taken from the adductor muscles of the hind legs.

Extraction of lipids. The lipids were usually extracted immediately; when, in the spring months, many samples were received simultaneously, those which could not be processed immediately were stored at $-20^{\circ}$ under nitrogen until examined. The calves were divided into young calves and older calves according to the weight of the carcass; when this weight was not available the weight of the heart was used as a criterion. The slaughter weights of young calves ranged from i I to $25 \mathrm{~kg}$, and those of older calves from 31 to $70 \mathrm{~kg}$. The heart weights ranged from 135 to $280 \mathrm{~g}$, and from 305 to $788 \mathrm{~g}$ respectively.

Extraction of lipids from tissues was carried out by the method of Folch, Lees \& Stanley (1957). All the solvents used were Analar grade commercial solvents. The tissue samples were homogenized in a Waring Blendor. After evaporation of solvents under reduced pressure, the crude extract was dissolved in light petroleum (b.p. 6o$80^{\circ}$ ) and dried over sodium sulphate.

Fractionation of lipids. The lipids were fractionated by means of silicic acid chro- 
matography. This was carried out by the method of Mead \& Gouze (I961). The course of elution was followed by weighing the solute portion from each fraction. Free and esterified cholesterol were determined by the method of Liebermann-Burchard (Abell, Levy, Brodie \& Kendall, 1952) and lipid phosphorus by the method of Bartlett (I959). After weighing and qualitative testing, the contents of the tubes were combined into five fractions: (I) hydrocarbons and sterol esters, (2) triglycerides, (3) free cholesterol, (4) partial glycerides and (5) phospholipids. The combined fractions were weighed, and the percentage composition of the extracted lipids was calculated.

Gas-liquid chromatography of fatty acids. The methyl esters of the fatty acids present in the triglycerides and phospholipids were prepared by the transesterification procedure of Stoffel, Chu \& Ahrens (1959). Analysis of the esters was performed with an Argon Chromatograph (W. G. Pye and Co Ltd, Cambridge).

Apietzon $\mathrm{L}$ grease was used in the chromatograph as a non-polar stationary phase and ethylene glycol adipate polyester as a polar stationary phase. The temperature was $200^{\circ}$ for apiezon columns and $180^{\circ}$ for ethylene glycol adipate columns. The retention times and carbon numbers of each peak on the chromatograms were calculated (Woodford \& van Gent, 1959-60). The samples were rechromatographed after bromination and hydrogenation according to the method of Farquhar, Insull, Rosen, Stoffel \& Ahrens (1959), but methyl alcohol was substituted for ethyl alcohol (Poukka, Vasenius \& Turpeinen, 1962). Fatty aldehydes were identified by the method of Farquhar (1962). Quantitative determination of fatty acid methyl esters was made by tracing the chromatograms on transparent millimeter paper and calculating the area of each peak in $\mathrm{mm}^{2}$. Tests of linearity of response were performed on polyester columns by chromatographing a mixture of fatty acid methyl esters, the exact composition of which was known.

\section{RESULTS}

Division of the samples into those derived from presumably healthy animals and those with degenerative changes was largely done on the basis of general appearance. Few microscopic preparations were made. Since no evidence of a seasonal effect was detected in any of the variables examined all the values for each group were treated as a homogeneous sample. The following abbreviations are used: $\mathrm{H}=$ heart muscle,

Table I. Lipid content of the heart muscle, the skeletal muscle and the liver of healthy calves and of calves suffering from muscular dystrophy

(Mean values with their standard errors)

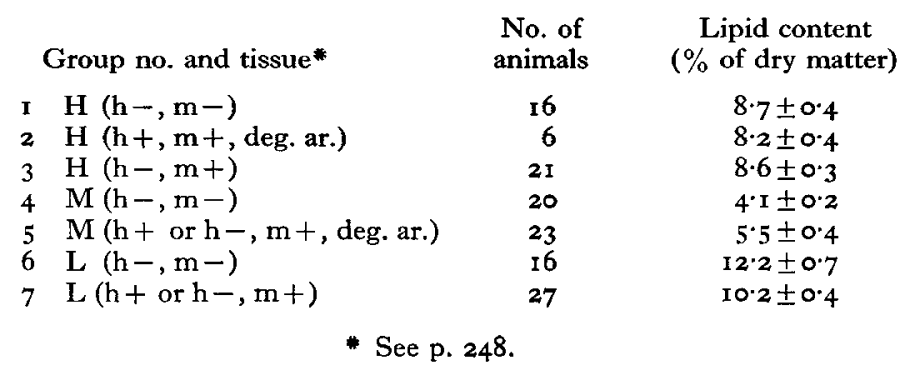


$\mathrm{M}=$ skeletal muscle, $\mathrm{L}=$ liver, $\mathrm{h}-=$ no pathological changes in the heart muscle, $\mathbf{h}+=$ pathological changes in the heart muscle, $\mathbf{m}-=$ no pathological changes in the skeletal muscle, $\mathbf{m}+=$ pathological changes in the skeletal muscle, deg. ar. $=$ degenerated areas.

The material was grouped as follows:

(I) Hearts of the healthy animals, $\mathrm{H}(\mathrm{h}-, \mathrm{m}-)$.

(2) Hearts of the animals with degenerative changes both in the heart muscle and in the skeletal muscle; degenerated areas, $\mathrm{H}(\mathrm{h}+, \mathrm{m}+$, deg. ar.).

(3) Hearts of the animals with degenerative changes in the skeletal muscle only, $\mathrm{H}(\mathrm{h}-, \mathrm{m}+)$.

(4) Skeletal muscle of the healthy animals, $M(\mathrm{~h}-, \mathrm{m}-)$.

(5) Skeletal muscle of the animals with degenerative changes; degenerated areas, $(\mathrm{h}+$ or $\mathbf{h}-, \mathrm{m}+$, deg. ar. $)$.

(6) Livers of the healthy animals, $\mathrm{L}(\mathrm{h}-, \mathrm{m}-)$.

(7) Livers of the animals with degenerative changes in the skeletal muscle or in the skeletal muscle and heart muscle, $\mathrm{L}(\mathrm{h}+$ or $\mathrm{h}-, \mathrm{m}+)$.

Table 2. Percentage of different lipid fractions from the total lipids of the heart muscle, the skeletal muscle and the liver of healthy calves and of calves suffering from muscular dystrophy

(Mean values with their standard errors)

Group no. and tissue*

I $\mathrm{H}(\mathrm{h}-, \mathrm{m}-)$

$2 \mathrm{H}(\mathrm{h}+, \mathrm{m}+$, deg. ar. $)$

$3 \mathrm{H}(\mathrm{h}-, \mathrm{m}+)$

$4 \mathrm{M}(\mathrm{h}-, \mathrm{m}-)$

$6 \mathrm{~L}(\mathrm{~h}-, \mathrm{m}-)$

$7 \mathrm{~L}(\mathrm{~h}+$ or $\mathrm{h}-, \mathrm{m}+)$
$5 \mathrm{M}(\mathrm{h}+$ or $\mathrm{h}-, \mathrm{m}+$, deg. ar. $)$

\begin{tabular}{|c|c|c|c|c|c|}
\hline $\begin{array}{l}\text { No. of } \\
\text { animals }\end{array}$ & $\begin{array}{l}\text { Phospho- } \\
\text { lipids }\end{array}$ & $\begin{array}{c}\text { Tri- } \\
\text { glycerides }\end{array}$ & $\begin{array}{l}\text { Partial } \\
\text { glycerides }\end{array}$ & $\begin{array}{l}\text { Chol- } \\
\text { esterol }\end{array}$ & $\begin{array}{l}\text { Chol- } \\
\text { esterol } \\
\text { esters }\end{array}$ \\
\hline I6 & $76 \cdot 0 \pm 2 \cdot 8$ & $9 \cdot 6 \pm x \cdot 8$ & $2.6 \pm 0.4$ & $6.7 \pm 0.3$ & $3.4 \pm 1.9$ \\
\hline 6 & $80.3 \pm 1.4$ & $6.5 \pm 0.7$ & $2.0 \pm 0.7$ & $7 \cdot 1 \pm 0.9$ & $4 \cdot I \pm I \cdot 9$ \\
\hline 2 I & $76 \cdot 8 \pm x \cdot 7$ & II. $0 \pm I \cdot 4$ & $2.1 \pm 0.2$ & $5.9 \pm 0.2$ & $4 \cdot 2 \pm I \cdot I$ \\
\hline 20 & $73 \cdot 9 \pm x \cdot 6$ & $I I \cdot I \pm I \cdot 4$ & $3.6 \pm 0.6$ & $7 \cdot 7 \pm 0 \cdot 3$ & $3.8 \pm 0.9$ \\
\hline 23 & $64.5 \pm 2 \cdot 6$ & $17.5 \pm 3^{\circ} 0$ & $2 \cdot 6 \pm 0.2$ & II' $2 \pm 0.7$ & $4 \cdot 2 \pm 0.6$ \\
\hline I7 & $62 \cdot 6 \pm 3 \cdot 8$ & $22 \cdot 3 \pm 3 \cdot 7$ & $4.6 \pm 0.5$ & $7 \cdot 6 \pm 0.5$ & $3 \cdot 3 \pm 0.4$ \\
\hline 27 & $78 \cdot 0 \pm x \cdot 0$ & $8 \cdot 8 \pm 0 \cdot 8$ & $2 \cdot 7 \pm 0.4$ & $7 \cdot 7 \pm 0 \cdot 4$ & $2 \cdot 7 \pm 0.3$ \\
\hline
\end{tabular}

Total lipid content of the heart muscle, the skeletal muscle and the liver

When the lipid content of the dry matter in the heart muscle, skeletal muscle and liver of young and older calves was investigated, it was found reasonable to treat the material as a whole, because no significant age differences were found.

As shown in Table I, the lipid content was about the same in the different groups of the heart muscle. In the degenerated areas of the skeletal muscle (group 5 ) it was higher $(P<0.01)$ than in the healthy controls (group 4$)$. Liver lipid content was higher $(P<0.02)$ in the healthy animals than in the affected animals. Student's $t$ test was used for the statistical analysis with probability of $\leqslant 0.05$ being accepted as revealing a significant difference. In the tables means and their standard errors are presented.

\section{Content of different lipid fractions}

The relative proportion of phospholipids in the total lipids was not significantly different in the different groupings of the heart muscle (Table 2). In the skeletal 
muscle the percentage of phospholipids was decreased in the degenerated areas as compared to the healthy muscles $(P<0.01)$. In the liver the proportion of phospholipids was higher in affected animals than in the healthy controls $(P<0.001)$.

The proportion of triglycerides appeared to be higher in the healthy hearts than in those that were affected $(9.6 \%$ and $11 \cdot 0 \%$ compared with $6.5 \%)$. Also in skeletal muscle, the percentage of triglycerides was 17.5 in affected muscle compared with $\mathrm{II}^{\cdot} \mathrm{I}$ in healthy muscle. This trend although not reaching significance was in the opposite direction from the effect in the hearts.

In the liver the proportion of triglycerides was significantly lower in diseased animals than in the healthy controls $(P<0.001)$. Also the proportion of partial glycerides was less in the livers of affected animals $(P<0.01)$. The relative proportion of free cholesterol was significantly higher in the degenerated areas of the skeletal muscle than in the healthy controls $(P<0.001)$.

In the cholesterol ester fraction no significant difference could be found.

\section{Fatty acid composition of phospholipids}

In Tables $3^{-8}$ the designations used for the structures of fatty acids are those of Farquhar $e t$ al. (1959). The corresponding aldehydes are marked with al. Only the major components are included.

Heart muscle. Group 2 was divided into two subgroups, a and b. Group 2 a corresponds to the previous group 2 (see p. 248 ). Group $2 \mathrm{~b}$ includes the samples with degenerative changes in the heart muscle only.

Investigation of the fatty acid composition of the heart muscle phospholipids revealed that the age of the animals was an important factor (Table 3). With increasing age the proportion of polyunsaturated fatty acids increased, especially that of linoleic acid, whereas the proportion of monounsaturated fatty acids, especially that of oleic acid, decreased. Of the saturated fatty acids the stearic acid content remained the same, but palmitic acid content decreased with increasing age.

The concentration of palmitoleic acid in group 2 a was significantly less than that in the healthy controls (group 1 ) (Table 3 ). In group $2 \mathrm{~b}$ the concentration of palmitic acid was greater than that in group $I$. In groups $2 a$ and $2 b$ the concentration of palmitaldehyde was lower than in the control group 1 . The differences in fatty acid composition were most marked when group 3 was compared with the healthy controls (group I). In group 3 the concentrations of both palmitaldehyde and stearaldehyde were greater than in group 1 . In group 3 the concentrations of the polyunsaturated fatty acids were much greater, whereas the concentrations of palmitic and the monounsaturated acids were much less than the corresponding concentrations of these acids in group $\mathrm{I}$.

When the results obtained from affected older calves (group $3^{\prime}$ ) were compared with those obtained from healthy controls (group $I^{\prime}$ ) it was found that the concentration of palmitic acid was significantly decreased in the affected calves (Table 3 ).

Skeletal muscle. Values obtained from the skeletal muscle of healthy young calves and healthy older calves are presented in Table 4.

The concentrations of polyunsaturated fatty acids, especially that of linoleic acid, 


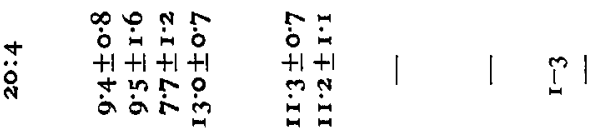

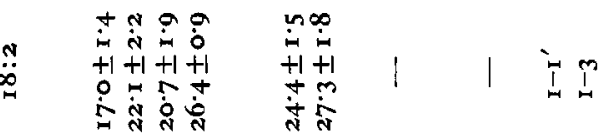

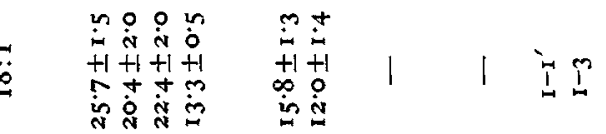

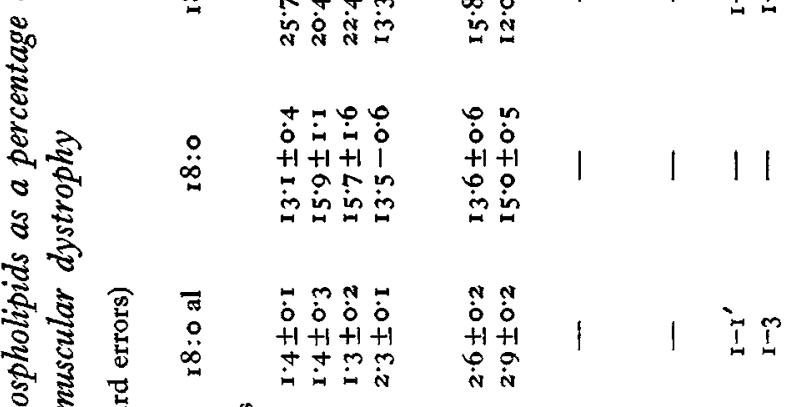

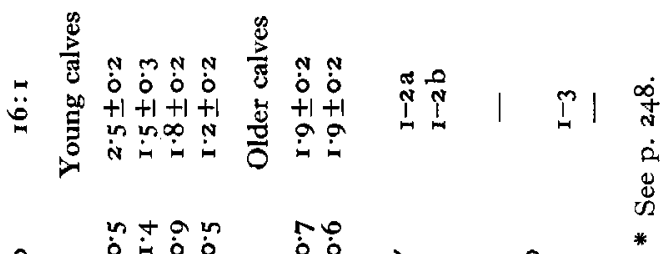

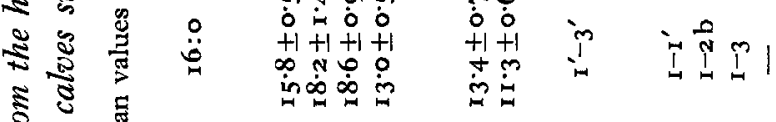

S.

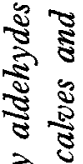

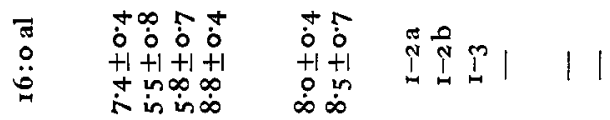

$\sum_{i}^{\infty}$

㟧 苨

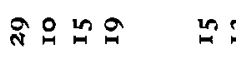

$m$

ปู

造

से

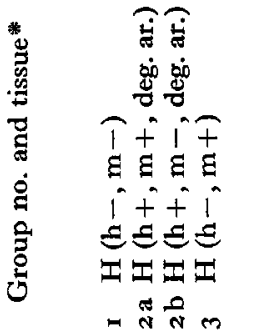

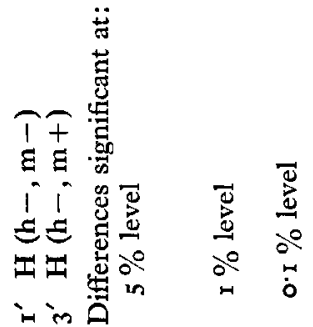


were much lower, whereas the contents of oleic and palmitoleic acids were much higher, in the young calves than in the older calves. The concentrations of stearaldehyde and stearic acid were lower in the skeletal muscle phospholipids of young calves than in those of older calves.

The fatty acid composition of the phospholipids in the degenerated skeletal muscle of young calves was markedly different from that in the healthy controls (Table 4). In the affected animals (group 5) the concentrations of stearic and the polyunsaturated acids were greater, but the concentrations of the monounsaturated acids were less, than in the control animals (group 4).

In contrast to young calves the fatty acid composition of the skeletal muscle from the affected older animals was only slightly different from that in the healthy controls (Table 4). The concentrations of arachidonic and stearic acids were, however, higher in the degenerated areas than in the healthy controls.

Liver. The fatty aldehydes, palmitaldehyde and stearaldehyde were present in very small amounts in the liver phospholipids. In the livers of young calves the phospholipids contained higher concentrations of palmitic acid, palmitoleic acid and oleic acid, whereas there were higher concentrations of stearic and linoleic acids in the phospholipids of the older calves (Table 5).

In affected young calves the concentrations of monounsaturated fatty acids in the liver phospholipids were decreased and linoleic acid concentration was increased (Table 5). In older calves no changes were found.

\section{Fatty acid composition of triglycerides}

Heart muscle. The fatty aldehydes which are often present in the phospholipid fraction were absent here, or were present only in very small amounts. Palmitic and oleic acids were the major fatty acids of the triglycerides. No seasonal differences were found, whereas the composition differed between young and older calves (Table 6). Triglycerides from heart muscle of young calves contained higher concentrations of palmitic and palmitoleic acids and lower concentrations of stearic and linoleic acids than those of older calves.

The fatty acid composition of the heart muscle triglycerides of the affected animals was only slightly different from that of the controls (Table 6). Nevertheless, the concentration of oleic acid in the triglycerides of the affected areas was significantly lower than in the heart muscle triglycerides in group I.

In group 3, the concentration of linoleic acid was higher and that of palmitic acid lower than in group $\mathrm{I}$. In older calves the changes were not significant.

Skeletal muscle. In the skeletal muscle triglycerides, palmitic and oleic acids were also the predominant fatty acids forming about $70 \%$ of the total fatty acids.

As shown in Table 7, differences in the composition of the fatty acids in the skeletal muscle were small when compared with those of the phospholipid fatty acids.

In the older calves, the concentration of stearic acid in the skeletal muscle triglycerides was higher than in the younger calves (Table 7). In the degenerated areas of young calves the concentration of linoleic acid was somewhat greater, and the concentrations of palmitic and oleic acids were somewhat less than in the healthy tissues. 


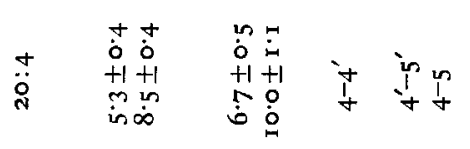

$\frac{\sqrt{0}}{0}$

$\frac{\pi}{\infty}$

ङั

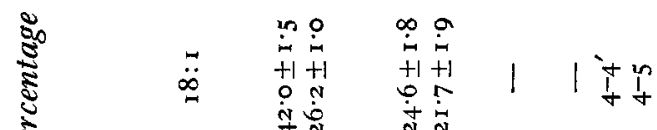

डे

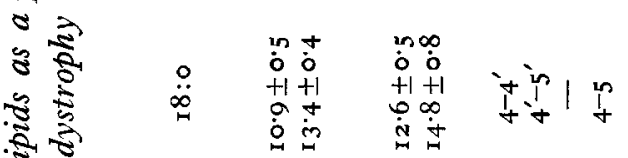

की

एँ

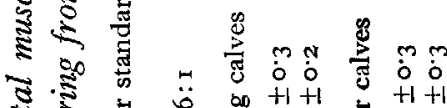

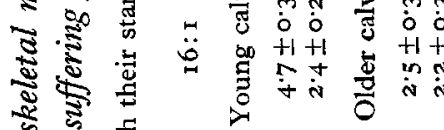

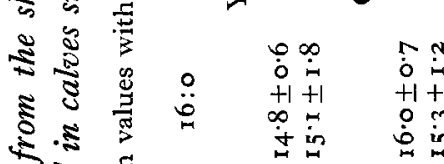

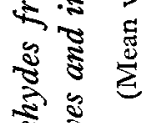

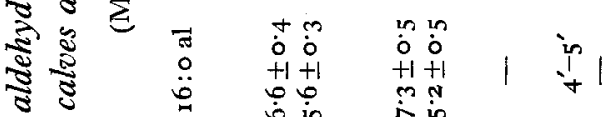

कर

농

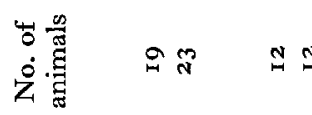

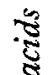

$\frac{5}{5}$

$\frac{\dot{0}}{2}$

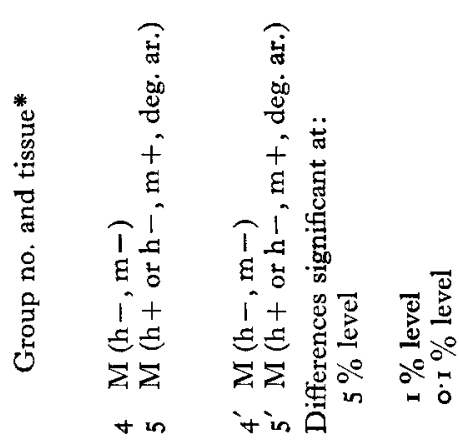

$\frac{0}{3}$

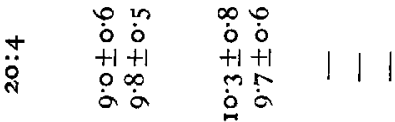

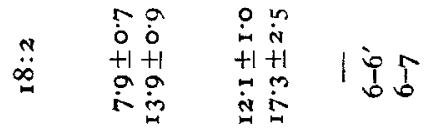

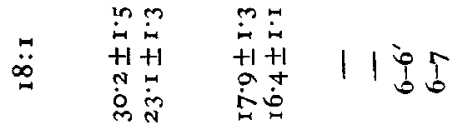

$\frac{2}{8}$

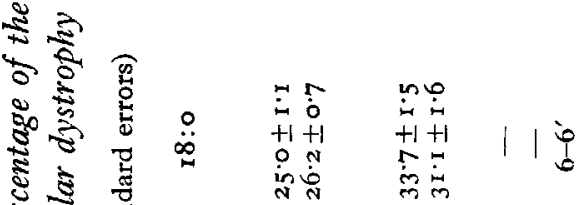
इ

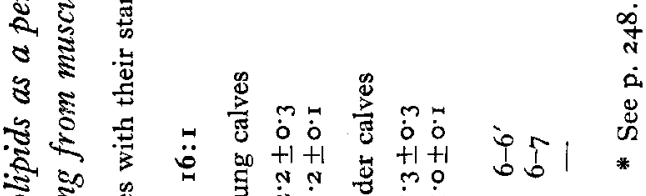

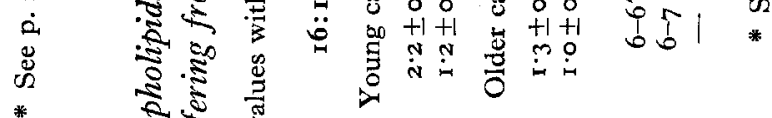

है है है

ปิ

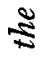

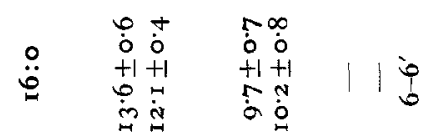

\$ิ

कू

हो

in

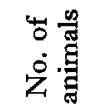

$\stackrel{\infty}{N} \quad m$

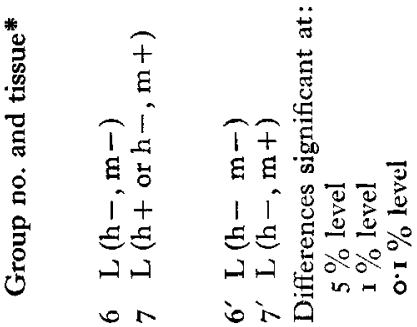


In older calves no differences in triglyceride fatty acid composition between healthy and degenerated muscle tissues could be found.

Table 6. Fatty acids from the heart muscle triglycerides as a percentage of the total in healthy calves and in calves suffering from muscular dystrophy

(Mean values with their standard errors)

\begin{tabular}{|c|c|c|c|c|c|c|}
\hline Group no. and tissue* & $\begin{array}{l}\text { No. of } \\
\text { animals }\end{array}$ & $16: 0$ & $16: 1$ & $18: 0$ & 18: I & $18: 2$ \\
\hline \multicolumn{7}{|c|}{ Young calves } \\
\hline I $\quad H(h-, m-)$ & 22 & $23 \cdot 4 \pm I .0$ & $3.1 \pm 0.3$ & $12 \cdot 9 \pm I \cdot 3$ & $44 \cdot 8 \pm I \cdot 9$ & $5.2 \pm 0.7$ \\
\hline $2 H(h+, m+$, deg ar $)$. & 13 & $26 \cdot 2 \pm I \cdot 3$ & $2 \cdot 3 \pm 0 \cdot 3$ & $I 5 \cdot I \pm I \cdot 4$ & $36 \cdot 9 \pm I \cdot 9$ & $7 \cdot 6 \pm r \cdot 3$ \\
\hline $3 H(h-, m+)$ & II & $19 \cdot 8 \pm 1 \cdot 3$ & $3 \cdot 1 \pm 0.4$ & $13 \cdot 6 \pm 0.7$ & $39 \cdot 5 \pm 2 \cdot I$ & II.T⿰㇒一乂 \\
\hline \multicolumn{7}{|c|}{ Older calves } \\
\hline $\mathrm{I}^{\prime} \mathrm{H}(\mathrm{h}-, \mathrm{m}-)$ & 9 & $18.7 \pm 0.7$ & $2 \cdot 2 \pm 0 \cdot I$ & $20 \cdot 7 \pm I \cdot 4$ & $41 \cdot 7 \pm 2 \cdot 5$ & $8 \cdot 5 \pm 0.7$ \\
\hline $3^{\prime} H(h-, m+)$ & 6 & $16 \cdot 3 \pm 0.7$ & $2 \cdot 8 \pm 0.3$ & $17 \cdot 1 \pm 2 \cdot 1$ & $41 \cdot 6 \pm 3 \cdot 8$ & $14 \cdot 0 \pm 3 \cdot 3$ \\
\hline \multicolumn{7}{|l|}{ Differences significant at: } \\
\hline $5 \%$ level & - & $\begin{array}{l}\mathrm{I}-3 \\
\mathrm{I}^{\prime}-3^{\prime}\end{array}$ & - & - & - & - \\
\hline I \% level & - & - & $\mathbf{I}-\mathbf{I}^{\prime}$ & $\mathbf{I}-\mathbf{I}^{\prime}$ & $I-2$ & $1-\mathbf{x}^{\prime}$ \\
\hline $0.1 \%$ level & - & $I-I^{\prime}$ & - & - & - & 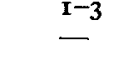 \\
\hline & & * See p. 2 & & & & \\
\hline
\end{tabular}

Table 7. Fatty acids from the skeletal muscle triglycerides as a percentage of the total in healthy calves and in calves suffering from muscular dystrophy

(Mean values with their standard errors)

\begin{tabular}{|c|c|c|c|c|c|c|}
\hline Group no. and tissue* & $\begin{array}{l}\text { No. of } \\
\text { animals }\end{array}$ & I6:0 & $16: 1$ & $18: 0$ & 18: 1 & $18: 2$ \\
\hline \multicolumn{7}{|c|}{ Young calves } \\
\hline $\mathrm{M}(\mathrm{h}-, \mathrm{m}-)$ & Io & $29 \cdot 2 \pm 1 \cdot 4$ & $5 \cdot 2 \pm 0.9$ & $10 \cdot 2 \pm 1 \cdot 2$ & $40 \cdot 4 \pm 2 \cdot 1$ & $3.5 \pm 0 \cdot 9$ \\
\hline$M(h+$ or $h-, m+$, deg. ar. $)$ & 19 & $23 \cdot 9 \pm 1 \cdot I$ & $3.4 \pm 0.3$ & $11 \cdot 4 \pm 0 \cdot 7$ & $34 \cdot 7 \pm 1 \cdot 4$ & $6 \cdot 0 \pm 0 \cdot 6$ \\
\hline \multicolumn{7}{|c|}{ Older calves } \\
\hline $\begin{array}{l}4^{\prime} \mathrm{M}(\mathrm{h}-, \mathrm{m}-) \\
5^{\prime} \mathrm{M}(\mathrm{h}+\text { or } \mathrm{h}-, \mathrm{m}+\text {, deg. ar. })\end{array}$ & $\begin{array}{l}8 \\
6\end{array}$ & $\begin{array}{l}22 \cdot 9 \pm 2 \cdot 4 \\
24 \cdot 3 \pm 3 \cdot 2\end{array}$ & $\begin{array}{l}4.7 \pm 0.9 \\
4.6 \pm 0.5\end{array}$ & $\begin{array}{l}15 \cdot 0 \pm 1 \cdot 5 \\
11 \cdot 9 \pm 2 \cdot 4\end{array}$ & $\begin{array}{l}4 \mathrm{r} \cdot 4 \pm 2 \cdot 9 \\
40 \cdot 3 \pm 3 \cdot 4\end{array}$ & $\begin{array}{l}7 \cdot 1 \pm 2 \cdot 4 \\
7 \cdot 1 \pm 1 \cdot 4\end{array}$ \\
\hline \multirow{3}{*}{$\begin{array}{l}\text { Differences significant at: } \\
5 \% \text { level } \\
\text { I \% level }\end{array}$} & & & & & & \\
\hline & - & - & $\longrightarrow$ & $4-4^{\prime}$ & $4-5$ & $4-5$ \\
\hline & - & $\begin{array}{c}4-5 \\
\text { See p. } 24\end{array}$ & - & & & \\
\hline
\end{tabular}

Liver. The results for the fatty acid composition of the liver triglycerides were similar to those for heart and skeletal muscle. No seasonal changes were found. The content of oleic acid was higher, and those of stearic acid and linoleic acid were lower, in young calves than in older calves (Table 8).

In samples from affected young animals the concentration of linoleic acid was greater, and that of oleic acid was less, than in the healthy controls (Table 8). In older calves no differences could be demonstrated. 
Table 8. Fatty acids from the liver triglycerides as a percentage of the total in healthy calves and in calves suffering from muscular dystrophy

(Mean values with their standard errors)

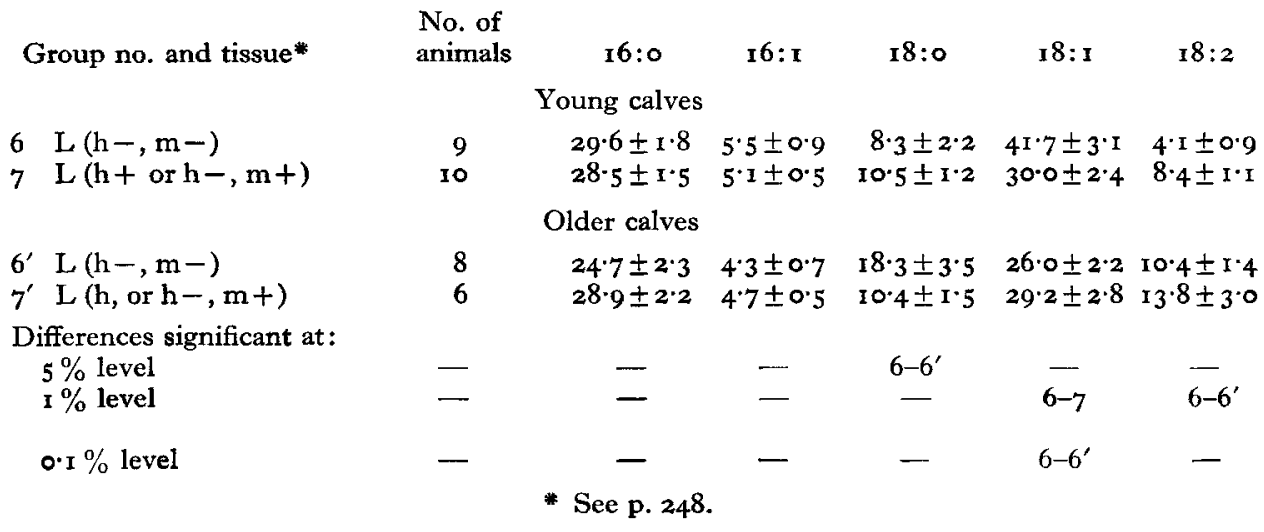

\section{DISCUSSION}

Phospholipids. The investigation now described showed that in the tissues of calves the content of linoleic acid increased and that of oleic acid decreased with increasing age. It is known that in non-ruminating animals and in young ruminants the fatty acid composition of tissues is influenced by diet (Machlin, I962, p. 255). The main diet of young calves is whole milk and skim milk. Also milk substitutes containing bone fat and tallow have come into use recently. Polyunsaturated fatty acids form only a small proportion of the total fatty acids of the milk fat of the cow, but monounsaturated fatty acids constitute about 30\% (Hilditch \& Williams, I964, p. 143). This and the synthesis de novo, especially during intra-uterine life, possibly explain the high content of monounsaturated fatty acids and the low content of polyunsaturated fatty acids in the tissues of young calves. On the other hand, hay, grass silage and concentrates, which are the main forage of older calves, are rich in $\mathrm{C}_{18}$-polyunsaturated fatty acids (Hilditch \& Williams, 1964, pp. I80 and 280). Unsaturated fatty acids are hydrogenated in the rumen, but such hydrogenation is not complete (Shorland, Weenink, Johns \& McDonald, 1957) and a part of the unsaturated fatty acids will certainly be consumed by the animals.

In young calves suffering from muscular dystrophy, the concentration of linoleic acid in the phospholipids was found to be increased in the tissues studied. On the other hand, in older calves no such increase was found. The observations that changes occurred also in the liver, which is not known to be an organ specifically affected in muscular dystrophy, and that in the heart muscle the concentration of linoleic acid showed the greatest increase in animals with degenerative changes in the skeletal muscle only, suggest that in young calves the increase in the concentration of linoleic acid was of a rather general nature.

The investigation now presented showed that the concentration of arachidonic acid in the tissues of diseased animals was often increased, but the increase was less consistent than that of linoleic acid. For example, in the skeletal muscle the concentration 
of arachidonic acid was increased in the degenerated areas both in young and older calves, whereas in the heart muscle the increase was not significant in the affected areas. The concentration of arachidonic acid was especially high in group 4 of the young calves as compared to the healthy controls. In liver, however, no changes in arachidonic acid concentration were found in young calves or in older calves.

The susceptibility of fatty acids towards peroxidation increases as the number of double bonds per fatty acid increases. Witting \& Horwitt (1964) found the relative rate of linoleic acid peroxidation in vivo to be forty times, and that of arachidonic acid I60 times, that of oleic acid. It is obvious that the increased concentrations of linoleic and arachidonic acids found in the present experiment increase the need for protecting factors.

According to Horwitt (1965), nutritional muscular dystrophy in mammals occurs only when certain of the polyunsaturated fatty acids in the muscle lipids reach a certain degree of 'peroxidizability' in a given period of time. Therefore it is obvious that an increased content of linoleic and arachidonic acids in tissues predispose young calves to muscular dystrophy.

A deficiency of vitamin $E$ or of selenium or of both is known to be associated with muscular dystrophy of calves. Besides vitamin E, selenium is also known to function as a biological antioxidant (Bieri, Dam, Prange \& Søndergaard, 196r; Hamilton \& Tappel, I963). Selenium antioxidants were found to possess 50 to 500 times the antioxidant activity of $\alpha$-tocopherol (Hamilton \& Tappel, I963). Antioxidants protect cellular unsaturated fatty acids against peroxidation and, on the other hand, the peroxidation products of unsaturated fatty acids destroy antioxidants.

Increased amounts of arachidonic acid have been found in the tissues of tocopheroldeficient rats (Bernhard, Leisinger \& Pedersen, 1963; Bieri, I964; Horwitt, 1965). In my work increased concentration of arachidonic acid was found in the degenerated areas of the skeletal muscle. In the corresponding areas of the heart muscle the difference was not significant, whereas in the heart muscle of the animals with degenerative changes only in the skeletal muscle was the difference highly significant. It is possible that in these tissues the metabolism of fatty acids of the linoleic acid family was disturbed because of possible vitamin E deficiency, and this deficiency was reflected in a higher content of arachidonic acid (Bernhard et al. I963).

Triglycerides. The differences between the fatty acid compositions of triglycerides in young and older calves were similar, as were those of the phospholipids but they were less pronounced. The higher concentration of stearic acid in older calves is obviously an indication of ruminal function. In diseased young animals the concentration of linoleic acid was increased and that of oleic acid was decreased, just as they were in the phospholipid fraction. The changes were, however, less marked.

Total lipid content and different lipid fractions. In agreement with the finding of Blaxter \& Wood (1952) in experimentally induced muscular dystrophy, the total lipid content was increased in the degenerated areas of the skeletal muscle. Blaxter \& Wood found also an increased amount of cholesterol in the skeletal muscle most affected. In my work the relative proportions of triglycerides and cholesterol were found to be increased and that of phospholipids decreased. 
The lipid content of liver in diseased animals was less than in healthy animals. The relative proportion of phospholipids was significantly higher and that of triglycerides was lower in the liver of affected animals than in the healthy controls.

Conclusions. The results of these experiments furnish evidence that both in muscular dystrophy produced experimentally and in the enzootic form of the disease, unsaturated fatty acids may play an important part. The factors that make the tissues accumulate unsaturated fatty acids are not known. Garton, Duncan, Blaxter, MacGill, Sharman \& Hutcheson (1956) showed that the unsaturated fatty acids in the milk fat of cows could not account for the incidence of muscular dystrophy in areas of Scotland where this disease occurs enzootically. Nevertheless, the milk was grossly deficient in tocopherol content. However, it is evident that the age of the animals is one factor of importance. The changes in the fatty acid composition of tissues in young animals growing rapidly are correspondingly rapid (Machlin, I962, p. 255). It is possible, therefore, that in young calves the rapid increase in the intake of polyunsaturated fatty acids together with deficiencies of vitamin $\mathrm{E}$ and selenium are important factors in inducing muscular dystrophy.

\section{REFERENCES}

Abell, L. L., Levy, B. B., Brodie, B. B. \& Kendall, F. E. (1952). F. biol. Chem. 195, 357.

Adams, R. S., Gullickson, T. W., Gander, J. E. \& Sautter, J. H. (1959). F. Dairy Sci. 42, 1552.

Adams, R. S., Gullickson, T. W., Sautter, H. J. \& Gander, J. E. (1954). F. Dairy Sci. 37, 655.

Adams, R. S., Sautter, J. H., Gullickson, T. W. \& Gander, J. E. (1959). F. Dairy Sci. 42, I580.

Andersson, P. (1960). Acta path. microbiol. scand. 48, Suppl. 134, p. I.

Barker, H. B., Wise, G. H. \& Jacobson, N. L. (1 952). J. Dairy Sci. 35, 507.

Bartlett, G. R. (1959). ₹. biol. Chem. 234, 466.

Bernilard, K., Leisinger, S. \& Pedersen, W. (1963). Helv. chim. Acta, 46, 1767.

Bieri, J. G. (1964). Fedn Proc. Fedn Am. Socs exp. Biol. 23, 394.

Bieri, J. G., Dam, H., Prange, I. \& Søndergaard, E. (I96I). Acta physiol. scand. 52, 36.

Blaxter, K. L., Brown, F., Wood, W. A. \& MacDonald, A. M. (I953). Br. F. Nutr. 7, 337.

Blaxter, K. L. \& McGill, R. F. (1955). Vet. Revs Annot. r, 91.

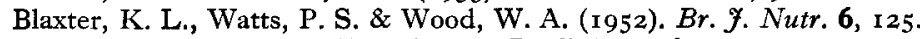

Blaxter, K. L. \& Wood, W. A. (1952). Br. F. Nutr. 6, 144.

Farquhar, J. W. (1962). Y. Lipid Res. 3, 21 .

Farquhar, J. W., Insull, W. Jr., Rosen, P., Stoffel, W. \& Ahrens, E. H. Jr. (1959). Nutr. Rev. I7, Suppl. p. 1 .

Folch, J., Lees, M. \& Stanley, G. H. S. (1957). F. biol. Chem. 226, 497.

Garton, G. A., Duncan, W. R. H., Blaxter, K. L., McGill, R. F., Sharman, G. A. M. \& Hutcheson, M. K. (1956). Nature, Lond., I77, 792.

Hamilton, J. W. \& Tappel, A. L. (1963). F. Nutr. 79, 493.

Hilditch, T. P. \& Williams, P. N. (1964). The Chemical Constitution of Natural Fats, 4 th ed. London: Chapman and Hall Ltd.

Horwitt, M. K. (1965). Fedn Proc. Fedn Am. Socs exp. Biol, 24, 68.

Machlin, L. J. (1962). In Lipids and their Oxidation. Chapter 14. [H. W. Schultz, editor.] Westport, Conn.: Avi Publishing Co.

Mead, J. F. \& Gouze, M. L. (196r). Proc. Soc. exp. Biol. Med. ro6, 4.

Oksanen, H. E. (1965). Acta vet. scand. 6, Suppl. 2.

Poukka, R., Vasenius, L. \& Turpeinen, O. (1962). F. Lipid Res. 3, 128.

Shorland, F. B., Weenink, R. O., Johns, A. T. \& McDonald, I. R. C. (I957). Biochem. F. 67, 328.

Slagsvold, L. \& Lund-Larsen, H. (1934). Norsk VetTidsskr. 46, 529.

Stoffel, W., Chu, F. \& Ahrens, E. H. (1959). Analyt. Chem. 31, 307.

Witting, L. A. \& Horwitt, M. K. (1964). F. Nutr. 82, I9.

Woodford, F. P. \& van Gent, C. M. (1959-60). J. Lipid Res. I, I88. 